\title{
Debates sobre ressarcimento e multas impostas às operadoras de planos de saúde: fontes de recursos para o SUS?
}

Discussions about the compensation and fines imposed on health insurance providers: funding sources for the SUS?

Debates acerca del resarcimiento y multas impuestas a las operadoras de seguros de salud: ¿fuentes de inversiones para el SUS?

Erick Alves Pereira Lopes ${ }^{1}$

RESUMO: Discutem-se as questões atinentes à legitimidade da Agência Nacional de Saúde Suplementar (ANS) em regulamentar o ressarcimento do SUS pelas operadoras de planos de saúde, a arrecadação de valores por aplicação de multas e a destinação desses valores ao custeio da própria agência. É defendida a opinião de que parte dos valores assim arrecadados seja destinado para o financiamento do SUS, havidas as alterações legislativas pertinentes.

Palavras-chave: Saúde Suplementar. Sistema Único de Saúde. Poder Regulamentador.

ABSTRACT: The paper discusses the legitimacy of the brazilian supplementary health care administration (ANS) to regulate the public health system (SUS) reimbursement by health insurance providers, the collection of values for fines and the destination of these values to fund the agency itself. It is advocated that part of the amount thus collected to be destined to finance the SUS, provided the pertinent legislative changes.

Keywords: Supplementary healthcare. Public Health System. Reimbursement Regulatory Power.

RESUMEN: Se discuten las cuestiones atinentes a la legitimidad de la Agencia Nacional de Salud Suplementar (ANS) en reglamentar el resarcimiento de SUS por las operadoras de planos de salud, recaudación de valores por aplicación de multas y el destino de esos valores para costear la propia agencia. Es defendida la opinión de que parte de los valores así recaudados sean destinados para el financiamiento de SUS, haciendo las alteraciones legislativas pertinentes.

Palabras-Ilave: Salud Suplementar. Sistema Único de Salud. Ressarcimiento e Poder Regulador.

\section{Introdução}

A saúde foi reconhecida como direito social, pelo artigo $6^{\circ}$ da Constituição da República Federativa do Brasil de 1988 - CRFB/1988 - (1). Em verdade, a atual carta política trouxe melhoria no que refere aos direitos humanos para os brasileiros e, dentre

\footnotetext{
1 Cirurgião-Dentista graduado pela Faculdade de Odontologia da Universidade do Grande Rio - UNIGRANRIO. Advogado graduado pela Faculdade de Direito da Universidade Cândido Mendes - UCAM. Analista Técnico do Departamento de Certificação de Entidades Beneficentes em Assistência Social do Ministério da Saúde. Email: ealopes@oi.com.br.
} 
estes, a proteção do direito à saúde. Neste diapasão, em seu artigo 196, a saúde foi reconhecida no país como direito de todos e dever do Estado, devendo ser garantido por meio de políticas sociais e econômicas que visem à redução do risco de doenças e outros agravos e, ainda, através de acesso universal igualitário às ações e serviços que possibilitem sua promoção, proteção e recuperação. Sendo assim, fica claro que a promoção, a proteção e a recuperação da saúde dependerão, sempre, de "uma determinada ação a ser tomada, direta ou indiretamente, pelos órgãos e instituições estatais" (2).

Segundo Dallari (3), o conceito de saúde adotado em documentos internacionais que tratam de direitos humanos é bastante amplo. Ultrapassa a primária definição de ausência de doença, contemplando a necessidade de assistência médica no caso de a doença já estar instalada e alcançando medidas que propiciem condições para plena recuperação do indivíduo. Mas ainda vai além, pensando também no direito a um nível de vida que evidencie a dignidade humana e a manutenção de condições adequadas a fim de que, neste nível, haja prevenção e tratamento de endemias e epidemias. Pensar em cuidados ambientais e laborais também faz parte desse universo.

$\mathrm{Na}$ visão de Vial (4), a efetivação de uma política de saúde com tamanha amplitude em um país com dimensões continentais como o Brasil - ampliadas pelas diferenças locoregionais - representa um desafio que precisa ser encarado pelos atores responsáveis pelo processo de elaboração, gestão e implementação, de modo que condições sejam criadas para que esse direito seja sentido e usufruído pela população em qualquer lugar do território nacional - lembrando que os problemas de saúde não são territorialmente limitados.

A organização estrutural do Sistema Único de Saúde (SUS) dispõe que as ações e os serviços públicos de saúde sejam realizados por instituições jurídicas estatais ou privadas. É um sistema que:

(...) define, harmoniza, integra e organiza as ações desenvolvidas por diversas instituições de direito público e privado existentes no Brasil, como o Ministério da Saúde, as Secretarias Estaduais e Municipais de Saúde, as Agências Reguladoras, entre outras entidades estatais ou privadas que prestam serviços públicos de saúde. (2).

Assim, há que se compreender que, conquanto as ações de saúde não sejam exclusivas do Estado, consoante leitura do art. 197 da CRFB/1988, exigem de forma permanente "o exercício do poder e da autoridade estatal para serem executadas 
conforme a necessidade da população, e não, de acordo com os interesses privados e econômicos" (5).

Com tamanha responsabilidade e atribuição, o financiamento dessas ações é de extrema importância, uma vez que sem recursos financeiros adequados e apropriados elas não serão corretamente implementadas. Este é um aspecto que influi decisivamente na efetivação do direito à saúde.

De fato, um sistema público de saúde como o SUS necessita de um financiamento público permanente, constante e suficientemente equilibrado para que possa cumprir com o seu importante objetivo de promoção, proteção e recuperação da saúde (2).

Neste contexto, este artigo se propõe a apresentar: (a) a necessidade de financiamento crescente para a saúde; (b) a interface legislativa existente entre a Saúde Suplementar e o SUS; (c) as questões atinentes à legitimidade da Agência Nacional de Saúde Suplementar (ANS) quanto aos poderes regulador e normativo; (d) os debates existentes acerca do ressarcimento das operadoras de planos de saúde ao SUS, bem como das multas aplicadas pela ANS às operadoras de planos de saúde e sua destinação.

Os métodos utilizados para a elaboração do artigo referem-se à revisão de literatura produzida por autores que trataram de temas que relacionam saúde suplementar, saúde pública e as problemáticas que envolvem o financiamento, o ressarcimento e a arrecadação de valores por aplicação de multas por agências reguladoras. Neste ínterim, cumpre informar ao leitor a dificuldade de identificar estudos que tratem especificamente da destinação das multas aplicadas pela ANS às operadoras e seguradoras de planos de saúde. A título de complementação, a fim de enriquecer a análise, também foram analisados alguns acórdãos exarados pelo Tribunal de Contas da União, que trataram da temática aqui apresentada.

\section{O Direito à Saúde e a Necessidade Crescente de Financiamento do SUS}

Na CRFB/1988, o financiamento à saúde está inserido no orçamento da seguridade social, como determina os artigos 194 e 195, de forma tripartite (União, Estados e Distrito Federal, e Municípios). O artigo 198, em seu $\S 3^{\circ}$, previu a necessidade de lei complementar que regulamentasse percentuais mínimos a serem aplicados pelos entes 
federativos em ações e serviços de saúde, e passados 12 anos da Emenda Constitucional 29, foi publicada a Lei Complementar 141/2012 (6).

No entanto, o novel diploma legal, que deveria possibilitar maior aporte de recursos financeiros ao SUS, na realidade apenas restringiu as hipóteses de interpretação do que poderia ser enquadrado como gastos em ações e serviços públicos em saúde. Chama a atenção, ainda, o fato de que o piso constitucional de aplicação de verbas na saúde pela União será o valor empenhado no exercício financeiro anterior, cujo valor de correção será a variação nominal do Produto Interno Bruto $(\mathrm{PIB})$, o que implica na não vinculação de fonte de recursos, ao contrário do que foi definido para os demais entes federados, com $12 \%$ da arrecadação dos Estados e Distrito Federal e 15\% da arrecadação dos Municípios a serem efetivamente aplicados na saúde.

Este quadro não animou alguns autores, que entendem que tal distribuição não trará melhoria financeira para alavancar os investimentos em saúde pelo SUS. Na opinião de Carvalho (7), a mencionada lei complementar reduziu em mais de $50 \%$ a responsabilidade federal no financiamento do SUS, mas ampliando em $20 \%$ a responsabilidade estadual e $50 \%$ a responsabilidade municipal, não deixando de lembrar que a União é, de fato, o órgão que realmente arrecada para a saúde, fora das competências tributárias dos demais entes.

A busca pela estabilidade do financiamento na saúde carrega em si a expectativa de aumento crescente deste investimento. Questões relacionadas ao subfinanciamento da saúde no Brasil são candentes e frequentemente ocupam espaços na mídia escrita e televisiva acerca da efetividade do direito à saúde, quer pela ótica da insuficiência da aplicação financeira para o alcance do objetivo proposto, quer pela ótica da efetividade dos meios utilizados pela gestão.

Neste momento, muito embora a tônica deste trabalho não seja a gestão, cumpre, mesmo assim, tecer breves considerações acerca deste importante componente na aplicação de recursos públicos, já que, de per si, o aumento do aporte de recursos financeiros para o financiamento da saúde não implica, necessariamente, na almejada e necessária melhora das condições de saúde do povo brasileiro. Fatores como a malversação de recursos públicos, ausência ou insuficiência de preparo técnico adequado aos gestores, burocracia excessiva, nomeações com critérios exclusivamente partidários e outros, indicam que o incremento financeiro deve acompanhar-se da qualificação da 
gestão. A temática do financiamento tem tamanha relevância que Assis (8) entende que o poder público precisa priorizar a alocação de recursos na área da saúde - e também na educação - ainda que prejudicando outras áreas não essenciais. E vaticina: "de fato, os recursos financeiros não são suficientes para as necessidades em saúde da população brasileira". (8).

Entretanto, além das dificuldades financeiras inerentes ao equilíbrio da equação necessidades/saúde/bem-estar, fatores nacionais e internacionais podem contribuir para comprometer a captação e destinação de recursos e aumentar a pressão para que haja mudanças na composição e distribuição orçamentárias, especialmente se estiverem empenhadas com os direitos sociais.

Ainda que presentes circunstâncias insusceptíveis de previsão, cabe ao gestor público bem cumprir as etapas de planejamento orçamentário e financeiro. A ausência de visão de futuro nesse processo compromete não apenas a viabilidade das políticas de ações e serviços em saúde, como tolhe cada cidadão do direito de ser protegido em sua saúde.

A LC 141/2012 (6) foi estruturada a partir do planejamento da política de saúde, confirmando tese de Bonavides (9), para quem os direitos sociais e o princípio da dignidade humana são tanto os direitos individuais quanto cláusulas pétreas. Destaca então que a falta de previsibilidade não pode ser confundida com imprevisibilidade, tendo o condão de apenas encobrir um "caráter essencialmente político da discussão e das decisões a tomar" nas palavras de Schuartz (10).

Mesmo quando há planejamento e não a imprevisibilidade, lida-se diuturnamente com a escassez de recursos. Diante da escassez ou, pelo menos, da insuficiência de recursos, surgem posições no sentido de focalizar "políticas concentradas em públicos-alvo seletivamente definidos, que se tornaram cada vez mais comuns a partir da década de 1980" (10).

E, no caso brasileiro, mesmo o país atravessando crises econômicas, o "universalismo se manteve normativamente robusto não apenas na retórica e nos discursos, mas também, em alguma medida, no âmbito dos processos decisórios de organizações governamentais e não governamentais nacionais e supranacionais" (10). 
Num contexto em que demandas crescentes confrontam um financiamento insuficiente, Cunha (11) alinha-se ao lado da defesa dos direitos sociais positivados na Lei Maior, ainda que na ocorrência de crise econômica. Afirma que:

(...) o princípio da proibição do retrocesso social tem como tarefa assegurar que a efetivação e aplicabilidade dos direitos sociais sejam um norte de atuação dos Estados perante a crise econômica mundial. (Cunha, 2013, p. 31).

Ratifica seu pensamento, afiançando ser dever dos "sujeitos históricos do campo da saúde garantir os direitos sociais constitucionalizados e os direitos humanos ratificados por pactos internacionais" (11).

Merece menção, pelo fato da judicialização da saúde ser temática atual e importante, a lição de Wang (12), que aborda a escassez de recursos e os custos para a efetivação dos direitos sociais como enfoque motivador das lides levadas à apreciação do Poder Judiciário.

Destarte, a escassez de recursos apontada pelos autores mencionados, frente às necessidades da nação brasileira pode indicar, entre outras considerações possíveis, que o financiamento da saúde deve ser acrescido de outras fontes - quer para a estabilidade, quer para a prospecção dos direitos. A própria CRFB/1988 (1) estabelece a necessidade crescente de financiamento conforme expresso no inciso IV do art. 194, ao mencionar a irredutibilidade de investimentos na seguridade social.

Ao admitir a necessidade de financiamento suficiente para a saúde, no que tange à relação entre o SUS e a Saúde suplementar, busca-se a análise das temáticas do ressarcimento ao SUS e a destinação das multas aplicadas pela ANS às operadoras de planos de Saúde.

Não se pretende, por óbvio, restringir hipóteses de acréscimo de financiamento, mas explicitar o ressarcimento das operadoras de planos e seguros de saúde ao SUS e as multas aplicadas pela ANS.

\section{O Ressarcimento das operadoras de planos/seguros de saúde ao SUS}

A Lei 9.656, de 3 de junho de 1998 (13), em seu artigo 32, estabeleceu o ressarcimento ao SUS pelas operadoras de saúde, cujo objetivo é reembolsar ações e serviços de saúde previstos e cobertos por contratos, cujos gastos tenham sido realizados 
pela rede pública. Assim, pelo texto legal, apenas e tão somente os atendimentos e serviços contratados com as operadoras de planos de saúde e não adimplidos por estas, mas prestados pela rede pública, seriam passíveis de serem ressarcidos ao SUS. Logo, se uma pessoa contrata assistência odontológica com uma operadora e tem atendimento médico-hospitalar em hospital público, esse ressarcimento não tem lugar, por não ter sido este o objeto do contrato.

A Lei 9.961, de 28 de janeiro de 2000, (14), criou a Agência Nacional de Saúde Suplementar (ANS), como órgão de regulação, normatização, controle e fiscalização das atividades que deveriam garantir a assistência suplementar à saúde. $O$ artigo 3o da mencionada lei determina a finalidade institucional da ANS:
A ANS terá por finalidade institucional promover a defesa do interesse público na assistência suplementar à saúde, regulando as operadoras setoriais, inclusive quanto às suas relações com prestadores e consumidores, contribuindo para o desenvolvimento das ações de saúde no País. (14).

A lei atribuiu, por conseguinte, poder regulamentar, normativo, de controle e de fiscalização à autarquia especial; por tal razão, o artigo $4^{\circ}$ elenca o rol de competências e as ratifica no artigo 10, ao atribuir à diretoria colegiada aptidão para a edição de normas sobre as matérias perfiladas.

Há debates sobre os poderes regulamentador e normativo conferidos à ANS. Sobre o poder regulamentar das agências reguladoras, Vidigal (15) conclui:

Portanto, o pensamento majoritário da doutrina brasileira reconhece, atualmente, que o poder regulamentar pode ser exercido tanto pelo Presidente da República, como expressamente previsto na Constituição Federal, assim como pelos Ministros de Estado e outras entidades e órgãos da Administração Pública. Em vista desse entendimento majoritário, não haveria óbices às agências reguladoras independentes deterem a competência regulamentar, desde que dentro de certos limites quanto ao alcance e conteúdo das normas por elas expedidas. (15).

Já em relação à função normativa das agências reguladoras, Vidigal (15) encontrou posicionamentos divergentes nos autores por ele estudados. Contudo, pondera e apresenta como pacífica a posição do Supremo Tribunal Federal (STF) em relação ao emprego do poder normativo por meio de standarts, o que o permitiu afirmar:

Independentemente da discussão a respeito da origem da legitimidade do poder normativo conferido às agências reguladoras, se por delegação legislativa ou pela própria missão a elas conferidas, o que de fato importa é que esses entes, para desempenharem o papel regulador, disponham de 
instrumentos adequados e necessários ao alcance de seus objetivos. Obviamente, não estamos falando de um poder sem limites e controles para as agências, mas uma flexibilidade e celeridade para que possam atuar de maneira eficiente - este sim um princípio constitucional que deve estar presente em todos os atos e contratos da Administração Pública - atingindo os fins para os quais foram criadas. (15).

Controvérsias também são observadas em torno do tema da fundamentação jurídica do ressarcimento. Autores que enfrentaram o assunto procuraram dissecá-lo sob os enfoques de obrigação tributária, obrigação civil e indenizatória e restituitória.

Reis (16) afirma categoricamente que o ressarcimento não é tributo. Portanto, não se trata de obrigação tributária. Garfinkel (17), em sentido contrário, vê o ressarcimento dentro da seara do direito tributário, uma vez que as peculiaridades constantes no artigo $3^{\circ}$ do Código Tributário nacional (CTN) estariam presentes em sua instituição e cobrança.

Garfinkel (17) afirma ainda que, para que seja caracterizada, a responsabilidade civil extracontratual, logo com natureza indenizatória, são necessários três pressupostos: a ilicitude da ação, o nexo de causalidade e o dano. A autora entende que, dos três, dois não estão presentes para ocorrer o ressarcimento: a ilicitude do ato e a existência de dano, o que afastaria esta fundamentação. Reis (16) também é de opinião que os pressupostos ensejadores da responsabilidade civil não estão presentes como causa do ressarcimento.

A cognição de Reis (16) interpreta o ressarcimento como tendo natureza restituitória, entendendo que se fundamenta no instituto do enriquecimento sem causa. Sua lógica é expressa desta forma:

(...) quando um cliente do plano de saúde usufrui os serviços públicos de saúde, a operadora se locupleta dos valores que teria gastado se tivesse prestado os serviços. Recebe as mensalidades dos clientes e não presta a assistência à saúde, logo, se enriquece sem justa causa. [...]. Por fim, há o nexo entre o empobrecimento do SUS e o enriquecimento da operadora, pois esta se locupleta às custas dos serviços públicos custeados por toda sociedade. Assim, ocorrendo o enriquecimento sem justa causa, nasce para a operadora a obrigação de restituir este valor ao SUS. Por uma questão de justiça e solidariedade social, não é compreensível que entidades privadas se locupletem às custas de toda população brasileira, afinal, como dito, os serviços públicos são custeados por toda sociedade. (16).

Seu pensamento se coaduna com Martins-Costa (18) que, ao analisar a função social dos contratos prevista no artigo 421 do Código Civil de 2002 (CC/02), afirma que esta função deve nortear o limite ao exercício da liberdade de contratar e igualmente 
compreendida "como razão de ser do exercício dessa mesma liberdade". Afirma, ainda, que quanto:

(...) mais essencial for, para as partes, o bem da vida subjacente ao objeto contratual (como no seguro de vida, no seguro-saúde, no fornecimento de água e energia elétrica, nos transportes etc.), maior deve ser a intervenção estatal (concretizando o princípio da função social), na sua tríplice esfera, para tutelar o bem contratado". (18).

Contratos que traduzem tal essencialidade são contratos que viabilizam para uma das partes "prestações essenciais" (18).

$\mathrm{Na}$ hipótese de quebra contratual, os efeitos do contrato inadimplido, no caso dos planos de saúde, não são sentidos apenas entre as partes contratantes; ecoam e fazem "reverberar as obrigações e os direitos assumidos pelos contratantes na esfera de terceiros, determinados ou indeterminados" (18). Aplicando sua lição in casu, reverberam sobre a parcela da população que não possui plano de saúde e depende do SUS.

Na contramão do que defende Reis (16), Dias [19] assevera que quem se locupleta é, na verdade, o SUS,

(...) a quem indistintamente incumbe prestar assistência integral a toda pessoa, sem ônus algum e como legítima expressão de um direito constitucional. [...] o SUS recebe para prestar esses serviços. (19).

Em seu trabalho, Dias [19] pugna pela ilegalidade do artigo 32 da Lei 9.656/1998. Já Tibúrcio (20) concorda em parte com a linha de pensamento de Reis (16), pois considera o princípio da vedação ao enriquecimento sem causa como um dos fundamentos da obrigação, cuja fonte jurídica imediata não é o artigo 884 do CC/2002, mas sim o artigo 32 da Lei 9.656/1998. Para este autor, o ressarcimento ao SUS é mais adequadamente assimilado com a utilização da teoria das externalidades, ao ver a aplicação deste artigo como

(...) decisão da sociedade de não tolerar a externalidade representada pelo benefício obtido pelas operadoras em decorrência do atendimento a um consumidor do plano de saúde pela rede pública de saúde. (20).

A obrigação lastreia-se, dessa forma, "no princípio democrático, no princípio da solidariedade e na função regulatória sobre as atividades de saúde suplementar" (20).

A discussão apresentada poderá ser ampliada ou mitigada, a depender do julgamento, pelo STF, da Ação Direta de Inconstitucionalidade (ADI) ํo 1.931, que 
questiona a constitucionalidade de vários dispositivos da Lei 9.656/1998, especialmente, o debatido artigo 32. Tramita no STF o Recurso Extraordinário (RE) 597064, que também discute o ressarcimento ao SUS.

Contudo, merece destaque o posicionamento já adotado pelo STF no julgamento plenário do pedido de liminar constante da ADI no 1.668, que questiona a constitucionalidade de dispositivos da Lei 9.472/1997 (21). Neste caso específico, o STF entendeu que a interpretação adequada é conforme a Constituição Federal nos incisos IV e $\mathrm{X}$ do artigo 19 desta Lei, sem redução do texto,

(...) com o objetivo de fixar exegese segundo a qual a competência da Agência Nacional de Telecomunicações para expedir normas subordina-se aos preceitos legais e regulamentares que regem a outorga, prestação e fruição dos serviços de telecomunicações no regime público e no regime privado (22).

Pela decisão liminar referente àquele dispositivo, a competência do poder normativo daquela agência reguladora foi admitida e mantida, atendidas a exigências legais para seu regular exercício. Embora a decisão final dessa ADI também se encontre pendente, este posicionamento sinaliza o reconhecimento, pela Corte Constitucional do país, da atuação da autarquia especial para editar normativa e, por via de consequência, fiscalizar seu cumprimento - pois o contrário resultaria na falta de efetividade.

À guisa de fomentar a discussão, de acordo com dados do Ministério da Saúde (MS) (23), a busca pelo ressarcimento promovida pela ANS, no desempenho de suas funções institucionais, durante todo o ano de 2013, arrecadou $R \$ 183,26$ milhões, enquanto de janeiro a julho deste ano, foram arrecadados $R \$ 184,03$ milhões. Ainda segundo esses dados, na última década $\mathrm{R} \$ 521,5$ milhões foram ressarcidos ao SUS.

Conforme se apura, os procedimentos relativos ao ressarcimento ao SUS derivam da Resolução Normativa RN № 185, de 30 de dezembro de 2008 (24), que em seu artigo 4º § 1ㅇ: dispõe:

O valor lançado no documento de autorização ou do registro do atendimento é obtido com base nas regras de valoração do SUS e na Tabela de Procedimentos Unificada do Sistema de Informações Ambulatoriais e do Sistema de Informação Hospitalar SAI/SIH - SUS. 
A inclusão ou exclusão de itens a serem ressarcidos pelas operadoras/seguros de saúde ao SUS estão à mercê do julgamento da Corte Suprema, ou da ampliação dos acordos entre o Ministério da Saúde e a ANS.

\section{Multas Impostas Pela ANS às Operadoras de Planos de Saúde}

A Lei 9.656/1998 (13), além de prever o ressarcimento ao SUS, também estabeleceu a aplicação de multas às operadoras que descumprem os contratos com os consumidores e normas da ANS para seu funcionamento. A disciplina, entre outras medidas sancionatórias, está presente no inciso II do artigo 25.

Diferentemente dos debates em torno do ressarcimento, a multa de conotação pecuniária decorre da função fiscalizatória empreendida pela ANS.

Ambos, contudo, são decorrentes da competência institucional da autarquia, regulamentar e normativa, de acordo com o diploma legal de sua gênese.

A Resolução Normativa - RN № 124, de 30 de março de 2006, exarada pela ANS (25) sob a rubrica de seu Diretor Presidente, dispõe sobre a aplicação de penalidades para as infrações à legislação dos planos privados de assistência à saúde, tipificando-as e definindo as formas de sanção; dentre elas, a multa pecuniária constante do inciso II do artigo $2^{\circ}$.

Sobre a destinação das multas aplicadas, o inciso III do artigo 17 da Lei 9.961/2000 (14) estabelece que "o produto da arrecadação das multas resultantes das suas ações fiscalizadoras" constitui receita da ANS, além de outras elencadas no referido artigo. Mas, apesar de constituir receita da autarquia especial, Melo (26), em seu estudo econômicofinanceiro sobre a ANS, afirmou que a Taxa de Saúde Suplementar por esta cobrada é a maior responsável por sua autonomia financeira.

Após ser arrecadada - quer pelo pagamento espontâneo, quer através de execução forçada após inscrição no Cadastro Informativo de Créditos não Quitados do Setor Público Federal (Cadin) - tem como destino o Tesouro Federal para ser utilizada nas despesas da ANS.

Tem-se, então, que a cominação pecuniária a atos infracionais praticados por operadoras de planos de saúde pela ANS pode ser vista como exercício regular do direito 
e do poder-dever oriundo de suas atribuições legais, para cuja inobservância omissiva ou comissiva poderá ser esta responsabilizada.

Neste tópico, talvez em razão de ser disciplina ainda recente, há dificuldades em encontrar doutrina já reconhecida. Logo, apegar-se-á à análise dos Acórdãos do Tribunal de Contas da União (TCU): 1.817/2010 - Plenário (27); 482/2012 - Plenário (28); e, 1.665/2014 - Plenário (29), afetos à atuação e gestão das agências reguladoras e outros órgãos da Administração Federal.

O Acórdão 1.817/2010 - Plenário (27), prolatado em 28/07/2010, avaliou o período de 2005 a 2009 e apresentou constatações e recomendações para que as agências sanassem as deficiências apontadas. Chama a atenção o item 4, onde o TCU expressa o entendimento de que as agências reguladoras aplicam multas no cumprimento de suas missões institucionais, ainda que criticando a eficiência das mesmas em arrecadá-las de modo que efetivamente ingressem nos cofres públicos:

Do cotejamento entre os valores das multas aplicadas e das efetivamente arrecadadas, verifica-se que um percentual pequeno, de 3,7\% em média, das penalidades pecuniárias aplicadas pelas entidades de regulação e fiscalização, tem ingressado de fato nos cofres públicos ao longo dos últimos anos, o que, além de representar a não efetivação de receitas públicas em valor considerável, pode implicar a minoração do desempenho obtido pelas referidas entidades no cumprimento de suas missões institucionais. (27).

Esse acórdão não refuta a atuação administrativa das agências, o que parece indicar não restar dúvida, para o TCU, quanto à sua legitimidade nas ações fiscalizatórias e respectiva aplicação de penalidade cominatória.

O referido acórdão chama a atenção para: (i) o baixo percentual de valores pagos em relação ao total de multas aplicado (no caso da ANS, 2,1\%); (ii) a baixa quantidade de inscrições no Cadin (ANS - 1,4\%); (iii) o baixo percentual de execuções fiscais oriundas de multas administrativas (ANS - 1,9\%); e, (iv) a elevada ocorrência de anulações destas. Ressalta, ainda, o risco de prescrição dos créditos decorrentes das multas - de acordo com o artigo 1-A da Lei 9.873/99, o prazo de prescrição para o exercício de ação punitiva pela Administração Pública Federal, direta e indireta, é de 5 anos, a contar da prática do ato, ou da sua cessação, se for infração permanente ou continuada -, o que pode minar a eficácia do poder de sanção. 
O Acórdão 482/2012 - Plenário, de 7/3/2012 (28), resulta do monitoramento decorrente do acórdão 1817/2010 (27). Destaca que, quanto às ações da ANS, foi possível observar a substituição de multas por termos de compromisso e ajustamento de conduta, além de desconto no caso de desistência de recurso, que explicariam a elevada anulação de multas administrativas apontadas anteriormente, e a modificação na organização e no processo de trabalho do setor de fiscalização.

Conquanto tenha indicado melhora no trabalho setorial de cada agência, o TCU determinou a inclusão, nos respectivos relatórios de gestão referentes aos exercícios de 2012 a 2016, seção específica para o tema "arrecadação de multas", de modo a apresentar informações acerca de pendências de inscrição no Cadin, número absoluto e percentual de processos de cobrança de multas com maior risco de serem prescritas, multas canceladas ou suspensas e os valores associados a elas, percentual de recolhimento de multas e medidas implementadas para a consecução das determinações.

Aprofundando-se na temática e reconhecendo sua importância para os cofres públicos, recomendou, inclusive, medidas para o aperfeiçoamento do Cadin.

As ações determinadas pelo TCU e seu o respectivo monitoramento resultaram no Acórdão 1.665/2014 - Plenário, de 25/06/2014 (29). Nele consta, delimitando-se os informes da ANS, que nos anos de 2011 e 2012 havia 760 pendências de inscrição no Cadin (não informou o total e o percentual destas pendências em relação ao montante), 910 processos sob risco de prescrição, sem constar a informação do total de processos existentes; o percentual em relação ao total; e o percentual de multas recolhidas. No que tange ao item multas canceladas ou suspensas, a ANS comunicou que foram 4, com valor total de $\mathrm{R} \$ 273$ mil reais, representando $1 \%$ do valor total. Contudo, não informou o valor total arrecadado em 2012, o valor das multas aplicadas e a razão entre eles. Destaca-se que o TCU manteve as determinações para as agências reguladoras, a serem monitoradas e avaliadas posteriormente.

A análise dos Relatórios de Gestão da ANS (23), (30) revela que, em 2012, 1.433 multas foram aplicadas, com valor notificado de $\mathrm{R} \$ 97.208 .023,88$; em 2013, 4.697 multas, com valor notificado de $\mathrm{R} \$ 378.608 .492,80$. Indica também que as modificações realizadas na organização e no processo de trabalho do setor de fiscalização abreviou o tempo de trâmite do processo até à última fase de cobrança, podendo chegar em até 45 dias à fase de inscrição em Dívida Ativa. Informa, ainda, que em 2013, R\$203.899.764,13 foram 
inscritos. No que refere a multas pagas e valores efetivamente arrecadados, detalha que em 2012 foram 352 multas quitadas, totalizando $\mathrm{R} \$ 26.644,974,67$; em 2013, 1.075 multas foram pagas, somando $\mathrm{R} \$ 98.266 .919,17$.

Os números revelam que 1.081 multas referentes a 2012 e 3.622 multas relativas a 2013 não foram pagas, não ingressando nos cofres públicos $R \$ 70.563 .049,21$ e $\mathrm{R} \$ 280.341 .573,63$, respectivamente. No total, reportando-se apenas esses anos, $\mathrm{R} \$ 350.904 .622,84$ deixaram de ser arrecadados. Segundo registros de 2000 a 2013, são 2.255 multas pagas e $\mathrm{R} \$ 155.880 .836,65$ arrecadados.

Nos mencionados relatórios há informações acerca dos recursos sobre multas aplicadas, inclusive aquelas canceladas por reconsideração total ou parcial, e aquelas que, mesmo com apresentação de recursos, foram mantidas. Informa que inexistem pendências de inscrição no Cadin, mesmo observados processos das duas instâncias administrativas, demonstrando que ocorreram avanços na ANS quanto à capacidade arrecadatória das multas aplicadas. Entretanto, como também visto, muito ainda precisa ser feito para que esta agência alcance o patamar de eficiência à altura da responsabilidade institucional a ela atribuída por lei.

\section{Considerações Finais}

O debate acerca da escassez de recursos e da necessidade de financiar adequadamente a saúde como forma de prover o direito fundamental também permeia a Saúde Suplementar. Num contexto em que teses sobre o limite orçamentário para o cumprimento da obrigação e a proibição do retrocesso social se digladiam, importa informar ao leitor que a LC 141/12 não trouxe novos recursos ao SUS.

Neste mesmo contexto, é preciso reconhecer, conforme se demonstrou no corpo do artigo, que as relações legais e das práxis entre o SUS e a ANS têm apresentado avanços no sentido de retornar aos cofres públicos valores monetários destinados à saúde, quer sejam oriundos do ressarcimento, quer das multas. Mas ainda não se mostram suficientes e dependem da solução à lide representada pela ADI no 1.931, em trâmite no STF.

Todavia, o foco do presente artigo diz especialmente da análise dos fundamentos jurídicos e discussões que cercam o ressarcimento das operadoras/seguros de saúde ao SUS e aplicação de multas pela ANS e suas respectivas destinações. Deste aspecto é possível concluir: 
1- Acerca do ressarcimento das operadoras/seguros de saúde ao SUS:

a. Os debates envolvendo o ressarcimento ao SUS apresentam dificuldades conceituais que tangenciam a universalização do acesso ao sistema público de saúde prevista na CRFB/1988, quando confrontado com o descumprimento de contratos celebrados com operadoras de planos/seguros de saúde para prestação positiva de serviços de saúde - reverberando, assim, na natureza jurídica do instituto "ressarcimento";

b. A ADI no 1.931 carece de julgamento pelo STF, a fim de dar cabo aos debates e estabelecer regra a ser seguida. Observada e mantida a tendência atual do STF, portanto, pelo reconhecimento da competência normativa, regulamentadora e fiscalizatória das agências, grande parte das controvérsias restará superada.

c. Num contexto em que se aguarda a posição do STF acerca da interpretação da lei, cumpre mencionar, somente em sede de considerações finais, que o debate acerca do ressarcimento tende a se alastrar ainda mais, tomada a especificidade trazida pela Lei 12.880/13 que determina a inclusão de tratamentos antineoplásicos de uso oral, procedimentos radioterápicos para tratamento de câncer e hemoterapia, como itens de cobertura obrigatória.

2- Acerca das multas aplicadas pela ANS às operadoras/seguros de saúde:

a. Apesar dos avanços observados, quer seja na arrecadação, quer seja nos procedimentos operacionais da agência reguladora, as recomendações do TCU para o aprimoramento da gestão e arrecadação de multas por parte da ANS, ainda deve ser perseguido;

b. Apreende-se da lei que os valores originados de multas arrecadadas são destinados ao custeio da própria ANS. Atualmente há expectativa, conforme pesquisa nos dados da Lei de Diretrizes Orçamentárias 2014, publicitados pela Secretaria de Orçamento Federal, que correspondam a 38\% dos recursos próprios para 2014, o que confirmaria que a Taxa de Saúde Suplementar é a principal fonte de recursos próprios da agência.

c. A aplicação das multas - ainda que por meio coercitivo - tem, entre suas finalidades, regular e adequar as operadoras que atuam no setor para amadurecer o mercado da saúde suplementar e que parcela dos valores arrecadados pode 
contribuir para efetivação do direito à saúde, uma vez que o motivo de aplicação das referidas multas, por vezes, reverbera sobre a sociedade.

Desta feita e pelos motivos expostos, há que se ponderar acerca da possibilidade de que parcela do quantitativo arrecadado a título de aplicação de multas seja destinado às ações e serviços de saúde diretamente, mediante alterações adequadas no diploma legal da ANS. O aprofundamento dos debates que circundam a tal sugestão tem por fundamentos: (i) a flagrante necessidade de aportes financeiros ao SUS; (ii) a inexistência, quer na CF, quer na legislação infraconstitucional, de impeditivos para que tal arrecadação seja considerada receita para o SUS; (iii) o financiamento da ANS se dá pelos Orçamentos Fiscal e da Seguridade Social, não causando, por conseguinte, nenhum prejuízo ao sustento da autarquia especial.

\section{Referências}

1 Brasil. Constituição da República Federativa do Brasil de 1988. Promulgada em 5 out. 1988. Disponível em:

$<$ http://www.planalto.gov.br/ccivil 03/constituicao/ConstituicaoCompilado.htm>. [Acesso em 18 ago. 2014].

2 Aith, F. A Saúde Como Direito de Todos e Dever do Estado: O Papel dos Poderes Executivo, Legislativo e Judiciário na Efetivação do Direito à Saúde no Brasil. Em: Aith, F; Saturnino, L T M; Diniz, M G A; Monteiro, T C (orgs). Direito Sanitário: Saúde e Direito, um Diálogo Possível. Belo Horizonte: ESP-MG, 2010, v.1, p. 73-142.

3 Dallari, S.G. Direito Sanitário. Disponível em:

<http://www.saude.ba.gov.br/conferenciaST2005/cdrom/CD\%20colet\%C3\%A2nea\%20I eis\%20e\%20textos/Artigos/10.doc . [Acesso em 10 abr. 2014].

4 Vial, S R M. O Pressuposto da Fraternidade como Condição para a Efetivação do Direito à Saúde. Em: Aith, F; Saturnino, L T M; Diniz, M G A; Monteiro, T C (orgs); Direito Sanitário: Saúde e Direito, um Diálogo Possível. Belo Horizonte: ESP-MG, 2010, v.1, p.107-142

5 Resende, C. O Modelo de Gestão do SUS e as Ameaças do Projeto Neoliberal. Disponível em: <http://www.cress 16.org.br/acervo/modelo de gestao.pdf>. [Acesso em 17 mai. 2014].

6 BRASIL. Lei Complementar no 141, de 13 de janeiro de 2012. Regulamenta o § 30 do art. 198 da Constituição Federal para dispor sobre os valores mínimos a serem aplicados anualmente pela União, Estados, Distrito Federal e Municípios em ações e serviços públicos de saúde; estabelece os critérios de rateio dos recursos de transferências para a saúde e as normas de fiscalização, avaliação e controle das despesas com saúde nas 3 (três) esferas de governo; revoga dispositivos das Leis nos 8.080, de 19 de setembro de 1990, e 8.689, de 27 de julho de 1993; e dá outras providências. Diário Oficial [da] 
República Federativa do Brasil, Brasília, DF, 16 jan. 2012. Disponível em:

$<$ http://www.planalto.gov.br/ccivil 03/leis/lcp/Lcp141.htm>. [Acesso em 25 out. 2014].

7 Carvalho, G. Financiamento da Saúde no Brasil à Luz da LC 141. Disponível em: $<$ http://www.idisa.org.br/img/File/GC-2013-ES-FINANCIAMENTO-I-

AT\%C3\%89\%20DEC\%207508\%20-AGO-\%202013\%20(1).ppt.>. [Acesso em 21 nov. 2014].

8 Assis, G. SUS Para Todos: Breves Reflexões Jurídico-Sociais Avanços e Desafios. Em: Aith, F; Saturnino, L T M; Diniz, MG A; Monteiro, T C (orgs). Direito Sanitário: Saúde e Direito, um Diálogo Possível. Belo Horizonte: ESP-MG, 2010, (1):143-186

9 Bonavides, P. Curso de Direito Constitucional. São Paulo: Malheiros, 2006. 808 p 10 Schuartz, L F. Universalização dos Fins e Particularização dos Meios: Política Social e Significado Normativo dos Direitos Fundamentais. Revista Direito GV, São Paulo: 5[2]: 359-376. Jul-Dez 2009.

11Cunha, J R A. Crash sanitário: os retrocessos na política de saúde frente à crise econômica e a alternativa de um princípio constitucional. Cad. lberAmer. Direito. Sanit. Brasília,2 (2), jul./dez. 2013

12 Wang, D W L. Escassez de Recursos, Custos dos Direitos e Reserva do Possível na Jurisprudência do STF. Revista Direito GV, São Paulo. 4[2]: 539-568. Jul-Dez 2008.

13 Brasil. Lei no 9.656, de 3 de junho de 1998.Dispõe sobre os planos e seguros privados de assistência à saúde. DOU, Brasília, DF, 4 jun. 1998. Disponível em:

$<$ http://www.planalto.gov.br/ccivil 03/leis/19656.htm>. [Acesso em 18 out. 2014].

14 Brasil. Lei no 9.961 de 28 de janeiro de 2000. Cria a Agência Nacional de Saúde Suplementar - ANS e dá outras providências. DOU Brasília, DF, 29 jan. 2000. Disponível em: <http://www.planalto.gov.br/ccivil 03/leis//9961.htm>. [Acesso em 18 out. 2014].

15 Vidigal, JAM. As agências reguladoras e seus poderes especiais no ambiente constitucional contemporâneo brasileiro. Monografia. Tribunal de Contas da União. 2004. 72 p. Disponível em: <http://portal2.tcu.gov.br/portal/pls/portal/docs/2053970.PDF>. [Acesso em 12 jul. 2014].

16 Reis, O M L S. Ressarcimento ao SUS: fundamento jurídico da cobrança. Dissertação (mestrado) - Universidade Federal de Viçosa, 2005.

17 Garfinkel, A. Natureza Jurídica da Obrigação de Ressarcimento dos Planos de Saúde ao Sistema Único de Saúde - SUS. Revista Direito GV, São Paulo.2 (2): 139-148. Jul.-Dez. 2006.

18 Martins-Costa, J. Reflexões sobre o Princípio da Função Social dos Contratos. Revista Direito GV, São Paulo. 1 (1): 41-66. Maio 2005.

19 Dias, JC. Alguns Aspectos Polêmicos do Ressarcimento ao Sistema Único de Saúde (SUS). Disponível em: <http://www.amog.org.br/amogarquivos/TCCPOS/Alguns-aspcetospolemicos-do-Ressarcimento-ao-SUS Julio-Cesar-Dias.pdf>. [Acesso em 14 ago. 2014].

20 Tibúrcio, D R. Ressarcimento ao SUS: uma proposta de delimitação da fonte e do fundamento da obrigação constante do art. 32 da Lei no 9.656/98. Disponível em: $<$ http://www.egov.ufsc.br/portal/conteudo/ressarcimento-ao-sus-uma-proposta-de- 
delimita\%C3\%A7\%C3\%A3o-da-fonte-e-do-fundamento-da-obriga\%C3\%A7\%C3\%A3ocons>. [Acesso em 26 ago. 2014].

21 Brasil. Lei no 9.472, de 16 de julho de 1997.Dispõe sobre a organização dos serviços de telecomunicações, a criação e funcionamento de um órgão regulador e outros aspectos institucionais, nos termos da Emenda Constitucional o 8, de 1995. DOU Brasilia, DF, 17 jul. 1997. Disponível em: <http://www.planalto.gov.br/ccivil 03/leis/19472.htm>. [Acesso em 18 out. 2014].

\section{Brasil. Supremo Tribunal Federal. Medida Cautelar na Ação Direta de} Inconstitucionalidade o 1.668 MC/DF (0002298-38.1997.0.01.0000). Requerente (s): Partido Comunista do Brasil - PC DO B; Partido dos Trabalhadores - PT; Partido Democrático Trabalhista - PDT; Partido Socialista Brasileiro - PSB. Relator: Ministro Marco Aurélio. Brasilia, DF, 20 de agosto de 1998. Disponível em: $<$ http://redir.stf.jus.br/paginadorpub/paginador.jsp?docTP=AC\&docID $=347202>$. [Acesso em 20 out. 2014].

23 Brasil. Agência Nacional de Saúde Suplementar. Relatório Anual de Gestão. Exercício de 2012. Disponível em:

$<$ http://www.ans.gov.br/images/stories/A ANS/Transparencia Institucional/Prestacao-deContas/Relatorios de gestao/relatorio-gestao-2012.pdf>. [Acesso em 20 ago. 2014].

24 Brasil. Agência Nacional de Saúde Suplementar. Resolução Normativa RN № 185, de 30 de dezembro de 2008. Institui o procedimento eletrônico de ressarcimento ao SUS, previsto no art. 32 da Lei $n^{\circ} 9.656$, de 3 de junho de 1998, e estabelece normas sobre a repetição de indébito e o repasse dos valores recolhidos a título de ressarcimento ao SUS. Disponível em:

$<$ http://www.ans .gov.br/index2.php?option=com legislacao\&view=legislacao\&task=TextoLe i\&format=raw\&id=1386 $>$. [Acesso em 15 out. 2014].

25 Brasil. Agência Nacional de Saúde Suplementar. Resolução Normativa - RN № 124, de 30 de março de 2006. Dispõe sobre a aplicação de penalidades para as infrações à legislação dos planos privados de assistência à saúde. Disponível em:

$<$ http://www.ans.gov.br/index2.php?option=com legislacao\&view=legislacao\&task=TextoLe i\&format=raw\&id=790>. [Acesso em14 set. 2014].

26 Melo, R M B. Estudo Econômico-Financeiro da Agência Nacional de Saúde Suplementar para o Equilibrio da Função de Órgão Regulador. Dissertação. Mestrado em Saúde Pública. Escola Nacional de Saúde Pública. Fundação Nacional Osvaldo Cruz. Rio de Janeiro. 2004. Disponível em:

$<$ http://www.ans.gov.br/images/stories/Materiais para pesquisa/Materiais por assunto/Dis sertacoes Estudo economico financeiro da ANS.pdf>. [Acesso em 5 set. 2014].

27 Brasil. Tribunal de Contas da União. Acórdão 1.817/2010 - Plenário.28/07/2010.

Disponível em:

$<$ https://contas.tcu.gov.br/juris/Web/Juris/ConsultarTextual2/Jurisprudencia.faces?anoAcor

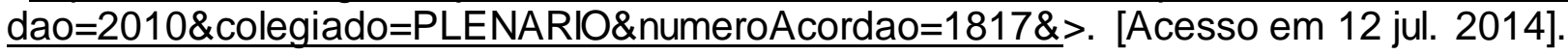

28 Brasil. Tribunal de Contas da União. Acórdão 482/2012 - Plenário, de 7/3/2012.

Disponível em:

$<$ https://contas.tcu.gov.br/juris/Web/Juris/ConsultarTextual2/Jurisprudencia.faces?colegiad o=PLENARIO\&numeroAcordao $=482 \&$ anoAcordao $=2012>$. [Acesso em 12 jul. 2014]. 
29 Brasil. Tribunal de Contas da União. Acórdão 1.665/2014 - Plenário, de 25/06/2014. Disponível em:

$<$ https://contas.tcu.gov.br/juris/Web/Juris/ConsultarTextual2/Jurisprudencia.faces?anoAcor

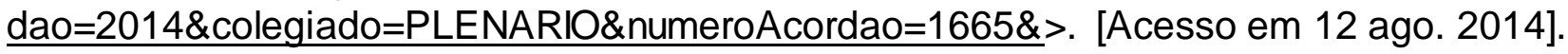
30 Brasil. Agência Nacional de Saúde Suplementar. Relatório de Gestão, 2013. Disponível em: <http://www.ans.gov.br/images/stories/A ANS/Transparencia Institucional/Prestacaode-Contas/Contas Publicas/2013-relatoriodegestao.pdf>. [Acesso em 20 out 2014].

Como citar este artigo:

Lopes EAP. Debates sobre ressarcimento e multas impostas às operadoras de planos de saúde: fontes de recursos para o SUS? Revista Cadernos Ibero-Americanos de Direito Sanitário. 2016 abr./junr, 5(2):23-42. 